\title{
Engineered fibroblast growth factor 19 protects from acetaminophen-induced liver injury and stimulates aged liver regeneration in mice
}

Gloria Alvarez-Sola ${ }^{1,8}$, Iker Uriarte ${ }^{1,8}$, Maria U Latasa ${ }^{2}$, Maddalen Jimenez ${ }^{2}$, Marina Barcena-Varela ${ }^{2}$, Eva Santamaría ${ }^{1}$, Raquel Urtasun ${ }^{2}$, Carlos Rodriguez-Ortigosa ${ }^{1,2}$, Jesús Prieto ${ }^{1,2}$, Fernando J Corrales ${ }^{2,3,7}$, Anna Baulies ${ }^{3,4,5}$, Carmen García-Ruiz ${ }^{3,4,5}$, Jose C Fernandez-Checa ${ }^{3,4,5}$, Pedro Berraondo ${ }^{6}$, Maite G Fernandez-Barrena ${ }^{1,2,9}$, Carmen Berasain ${ }^{\star, 1,2,9}$ and Matías A Avila ${ }^{\star, 1,2,9}$

The liver displays a remarkable regenerative capacity triggered upon tissue injury or resection. However, liver regeneration can be overwhelmed by excessive parenchymal destruction or diminished by pre-existing conditions hampering repair. Fibroblast growth factor 19 (FGF19, rodent FGF15) is an enterokine that regulates liver bile acid and lipid metabolism, and stimulates hepatocellular protein synthesis and proliferation. FGF19/15 is also important for liver regeneration after partial hepatectomy (PH). Therefore recombinant FGF19 would be an ideal molecule to stimulate liver regeneration, but its applicability may be curtailed by its short half-life. We developed a chimaeric molecule termed Fibapo in which FGF19 is covalently coupled to apolipoprotein A-I. Fibapo retains FGF19 biological activities but has significantly increased half-life and hepatotropism. Here we evaluated the proregenerative activity of Fibapo in two clinically relevant models where liver regeneration may be impaired: acetaminophen (APAP) poisoning, and $\mathrm{PH}$ in aged mice. The only approved therapy for APAP intoxication is $\mathrm{N}$-acetylcysteine (NAC) and no drugs are available to stimulate liver regeneration. We demonstrate that Fibapo reduced liver injury and boosted regeneration in APAPintoxicated mice. Fibapo improved survival of APAP-poisoned mice when given at later time points, when NAC is ineffective. Mechanistically, Fibapo accelerated recovery of hepatic glutathione levels, potentiated cell growth-related pathways and increased functional liver mass. When Fibapo was administered to old mice prior to PH, liver regeneration was markedly increased. The exacerbated injury developing in these mice upon PH was attenuated, and the hepatic biosynthetic capacity was enhanced. Fibapo reversed metabolic and molecular alterations that impede regeneration in aged livers. It reduced liver steatosis and downregulated p21 and hepatocyte nuclear factor $4 \alpha(H n f 4 \alpha)$ levels, whereas it stimulated Foxm1b gene expression. Together our findings indicate that FGF19 variants retaining the metabolic and growth-promoting effects of this enterokine may be valuable for the stimulation of liver regeneration.

Cell Death and Disease (2017) 8, e3083; doi:10.1038/cddis.2017.480; published online 5 October 2017

The liver fulfils an essential role in the detoxification of metabolites and exogenous compounds. In this process, noxious stimuli may be generated, eventually causing hepatocellular death. To cope with this situation the liver has developed an extraordinary regenerative capacity unparalleled by other organs. ${ }^{1}$ Liver regeneration also manifests as a vigorous response after surgical removal of part of the tissue. $^{2,3}$ Therefore, in the context of parenchymal damage or tissue resection a potent hepatoprotective and regenerative reaction is triggered within the liver as well as systemically. ${ }^{1,4}$ Liver regeneration involves survival and pro-mitogenic mechanisms activated by fluctuating metabolites, cytokines and growth factors in an intricate cellular and molecular crosstalk. ${ }^{1,2}$ The regenerative response usually concludes with the restoration of histological integrity and hepatic function, which is essential for homeostasis and survival. ${ }^{5,6}$ However, there are circumstances in which the regenerative capacity of the liver is overwhelmed by the extent of parenchymal destruction, or diminished by pre-existing conditions that amplify injury and hamper tissue repair. ${ }^{7}$

In the clinical context, acute liver injury leading to impairment of liver function and regenerative capacity may occur under different situations. Among them drug intoxication is a leading cause, with acetaminophen (APAP) overdose accounting for almost $50 \%$ of all cases in the western world. $^{8}$ Currently, the only approved drug to treat APAP intoxication is $\mathrm{N}$-acetylcysteine (NAC). ${ }^{8,9}$ The efficacy of NAC is mostly based on its positive effects on hepatic glutathione

\footnotetext{
${ }^{1}$ CIBERehd, Instituto de Salud Carlos III, Clinica Universidad de Navarra, Avda, Pio XII, n 36, Pamplona 31008, Spain; ${ }^{2}$ Hepatology Programme, CIMA, Idisna, Universidad de Navarra, Avda, Pio XII, n 55, Pamplona 31008, Spain; ${ }^{3}$ CIBERehd, Instituto de Salud Carlos III, Barcelona, Spain; ${ }^{4}$ Department of Cell Death and Proliferation, Instituto de Investigaciones Biomédicas de Barcelona, CSIC and Liver Unit-Hospital Clinic-IDIBAPS, Barcelona, Spain; ${ }^{5}$ Research Center for ALPD, Keck School of Medicine, University of Southern California, Los Angeles 90033, CA, USA and ${ }^{6}$ Immunology and Immunotherapy Programme, CIMA, Idisna, Universidad de Navarra, Avda, Pio XII, n 55, Pamplona 31008, Spain

*Corresponding author: C Berasain or MA Avila, Hepatology Programme, CIMA-University of Navarra, Avda, Pio XII, n 55, Pamplona 31008 , Spain. Tel: +34 948 194700; Fax: +34 948 194717; E-mail: cberasain@unav.es or maavila@unav.es

${ }^{7}$ Current address: Centro Nacional de Biotecnología (CNB-CSIC). C/ Darwin 3, Madrid 20049, Spain.

${ }^{8}$ These authors contributed equally to this work.

${ }^{9}$ These authors share senior authorship.

Received 02.6.17; revised 31.7.17; accepted 09.8.17; Edited by M Piacentini
} 
(GSH) levels, which are depleted by the toxic APAP metabolite $N$-acetyl-p-benzoquinone (NAPQI). NAPQI triggers mitochondrial dysfunction, oxidative stress and massive hepatocyte necrosis. ${ }^{10}$ Hepatocellular death unlashes the activation of the innate immune system, a reaction increasingly recognized as protective and pro-regenerative rather than a deleterious response. ${ }^{9}$ Clinical observations indicate that regeneration of new parenchymal cells appears essential for survival after APAP-induced acute liver failure. ${ }^{11}$ Therefore, understanding the endogenous mechanisms of liver protection and regeneration may allow the identification of therapeutic strategies. $^{12,13}$ In this line of thinking, enhancement of the natural regenerative response by the experimental administration of growth factors and cytokines has recently shown promising effects on APAP toxicity. ${ }^{14-18}$ Exploring new therapeutic approaches is important, as NAC is only effective when administered early after APAP intoxication and liver transplantation is the sole therapeutic alternative in severe cases. ${ }^{10,13}$

Another clinical scenario in which liver regeneration may fail is when partial hepatectomy $(\mathrm{PH})$ is performed in diseased or aged livers for the removal of primary or metastasic tumors, or after segmental liver transplantation. ${ }^{7}$ For instance, patients with fatty livers, a condition usually accompanied by cholestasis, frequently present a worse outcome after resection. $^{19,20}$ This impaired response has been widely validated in experimental models of hepatosteatosis. ${ }^{21,22}$ Similarly, liver regeneration is compromised in elderly patients and aged rodents. ${ }^{23-25}$ The mechanisms underlying the decline in the regenerative capacity of aged livers are not completely

known, although some epigenetic and intracellular signaling mechanisms leading to cell cycle alterations have been exposed. ${ }^{23,26-30}$ Unraveling these fundamental processes may lead to the development of pharmacological therapies to alleviate age-related liver regeneration defects, as experimentally demonstrated in recent studies. ${ }^{23,29,31}$ With an increasingly aging population it is important to devise such therapies.

We and others have recently shown the significant role played by the enterokine fibroblast growth factor 19 (FGF19; FGF15 in rodents) ${ }^{32,33}$ and its receptor FGFR4 in liver regeneration after $\mathrm{PH}^{34-36} \mathrm{FGF} 15 / 19$ controls bile acids (BA) homeostasis, reduces liver fat accumulation and enhances hepatocyte survival and proliferation. FGF15/19 delivery from viral vectors improves mouse survival after extensive liver resection, ${ }^{22,34}$ and recombinant FGF19 protects from cholestatic liver injury and lipotoxicity. ${ }^{22,37,38}$ From a a
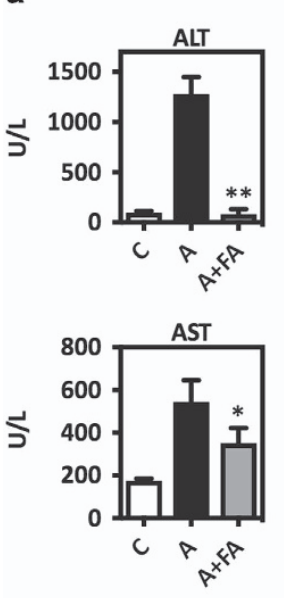

b
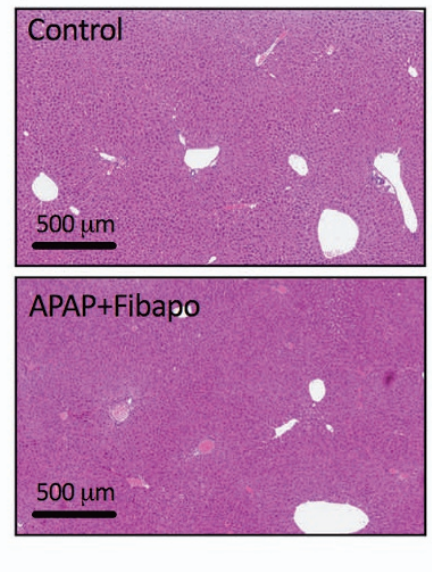
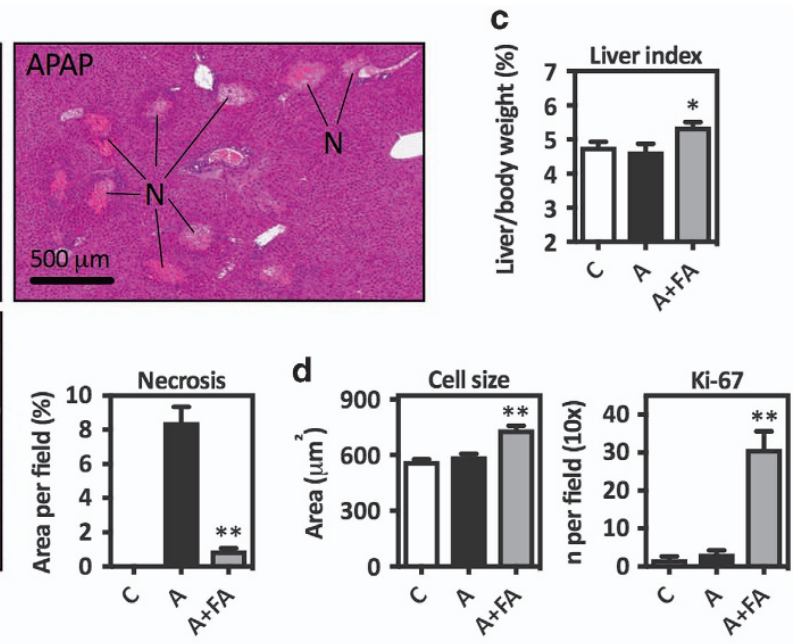

e
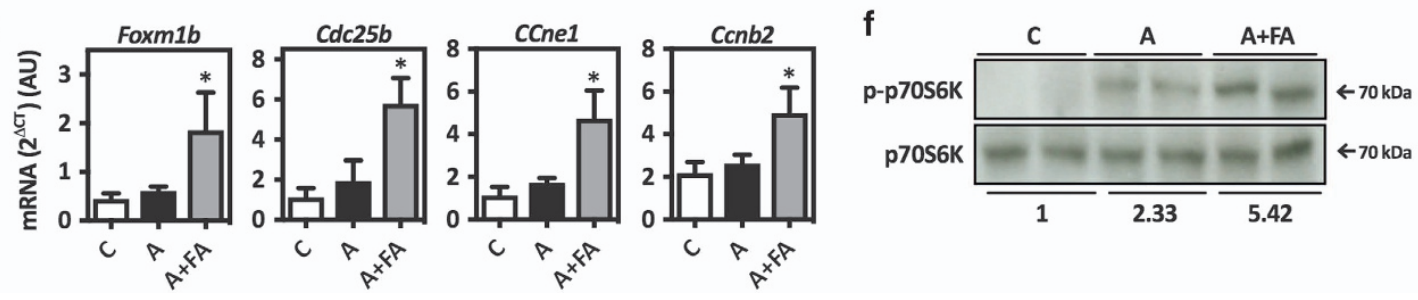

Figure 1 Fibapo administration protects from APAP-induced liver injury. (a) Serum levels of ALT and AST in control mice (C), mice that were treated with APAP (A) (300 mg/ $\mathrm{kg}$ ) or mice that 2, 10 and $24 \mathrm{~h}$ after APAP injection received three doses of Fibapo (A+FA) ( $n=7$ mice per group). Blood and tissue samples were taken $36 \mathrm{~h}$ after APAP administration, when mice were killed. (b) Representative H\&E-stained liver tissue sections from mice treated as described. Necrotic areas are indicated (N). Graph shows the quantification of tissue necrotic areas. (c) Liver weight to body weight ratio (liver index) in mice from the different treatment groups described. (d) Left panel shows the average hepatocyte size and right panel shows the quantification of hepatocytes with Ki-67-positive nuclei in liver tissue sections from mice treated as described. (e) Quantitative PCR analysis of the expression of cell cycle-related genes in liver tissues from mice treated as described. (f) Western blot analysis of phospho-p-70S6K (p-p-70S6K) and total p70S6K levels in liver tissue samples from mice treated as described. Representative blots are shown. ${ }^{*} P<0.05$ and ${ }^{*} P<0.01$ versus APAP-treated mice. AU: arbitrary units 
a

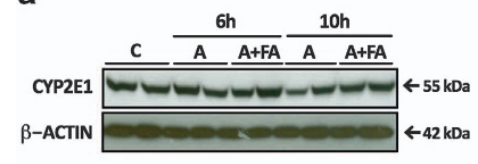

d

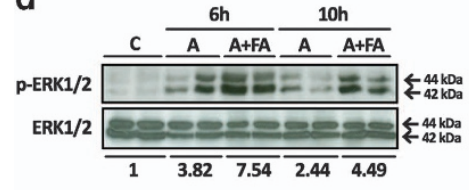

b

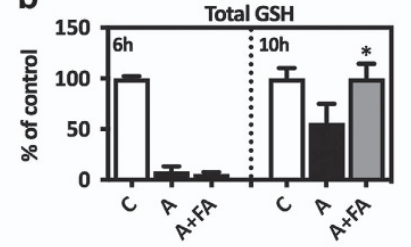

C

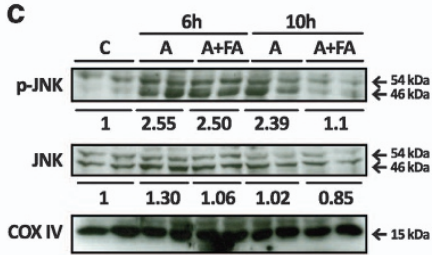

e
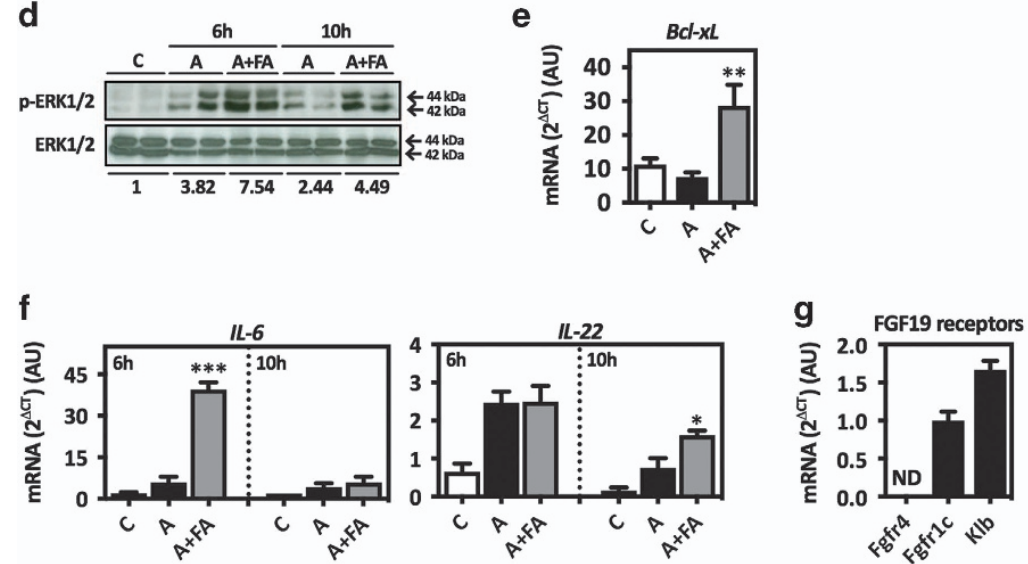

Figure 2 Effects of Fibapo on early hepatic responses to lethal APAP doses. (a) Western blot analysis of CYP2E1 expression in the liver of mice ( $n=7$ per group) treated with $\operatorname{APAP}(\mathrm{A})(500 \mathrm{mg} / \mathrm{kg})$ that $2 \mathrm{~h}$ later received a single dose of Fibapo (FA). Mice were killed 6 and $10 \mathrm{~h}$ after APAP injection. Representative blots are shown. (b) Total glutathione (GSH) levels in the livers of mice treated as described and killed at $6 \mathrm{~h}$ and $10 \mathrm{~h}$ after APAP injection. (c) Western blot analysis of phospho-JNK (p-JNK) and total JNK levels in mitochondrial fractions obtained from livers of mice treated as described and killed at 6 and $10 \mathrm{~h}$ after APAP injection. COX IV protein levels were analyzed as loading control. Representative blots are shown. (d) Western blot analysis of phospho-ERK1/2 (p-ERK1/2) and total ERK1/2 levels in liver homogenates obtained from mice treated as described and killed at 6 and $10 \mathrm{~h}$ after APAP administration. Representative blots are shown. (e) Quantitative PCR analysis of $B c l-x L \mathrm{mRNA}$ levels in the liver of mice treated as described and killed at $10 \mathrm{~h}$ after APAP administration. (f) Quantitative PCR analysis of $I L-6$ and $I L-22 \mathrm{mRNA}$ levels in the liver of mice treated as described and killed at $6 \mathrm{~h}$ and $10 \mathrm{~h}$ after APAP administration. (g) Quantitative PCR analysis of the mRNA levels of the FGF19 receptors FGFR4, FGFR1c and co-receptor Klb in primary cultured murine macrophages. AU: arbitrary units. ND: not detected. ${ }^{*} P<0.05,{ }^{* \star} P<0.01$ and ${ }^{* \star *} P<0.001$ versus APAP (A)-treated mice

translational perspective these characteristics identify FGF15119 as a promising tool to improve liver regeneration under unfavorable conditions. However, FGF15/19 has a very short half-life with a high glomerular filtration rate. ${ }^{38}$ To circunvent this limitation we recently developed a chimaeric molecule based on the fusion of FGF19 with apolipoprotein A-I (ApoA-I) named Fibapo. ${ }^{22}$ The ApoA-I moiety confers Fibapo increased biological stability, and targets it to the liver through the interaction of the ApoA-I moiety with the hepatocyte's scavenger receptor class B type I. ${ }^{22}$ Here, we demonstrate the applicability of Fibapo for the treatment of APAP-induced liver injury and in the stimulation of aged liver regeneration.

\section{Results}

Fibapo protects from APAP toxicity and enhances liver regeneration. To analyze the effect of Fibapo on APAP toxicity, mice received three doses of the recombinant protein 2, 10 and $24 \mathrm{~h}$ after APAP $(300 \mathrm{mg} / \mathrm{kg}$ ) injection. Serum transaminases levels and centrilobular liver necrosis were reduced by Fibapo administration (Figures 1a and b). Liver injury elicited by APAP is followed by a compensatory regenerative response. ${ }^{39}$ We found a clear increase in liver weight to body weight ratio (Figure 1c), hepatocyte cell size and hepatocellular proliferation (Ki-67 labeling) upon Fibapo treatment (Figure 1d and Supplementary Figure 1). Consistently, the expression of cell cycle regulatory genes Foxm1b,
Cdc25b, Ccne1 and Ccnb2 was induced (Figure 1e and Supplementary Figure 2). To a great extent, FGF19 regulates hepatocellular proliferation and growth through the activation of the mechanistic target of rapamycin complex 1 (mTORC1)p-70S6 kinase (p70S6K) pathway. ${ }^{22,40}$ We observed that mice treated with Fibapo after APAP administration showed increased p-p70S6K levels (Figure 1f). The hepatic expression levels of interleukin 10, a cytokine involved in the endogenous hepatoprotective response to APAP intoxication, ${ }^{41}$ was also markedly induced (Supplementary Figure 3).

To further test the hepatoprotective effects of Fibapo we treated mice with a higher dose of APAP $(500 \mathrm{mg} / \mathrm{kg})$, which induces significant mortality (see below). Two hours after APAP injection mice received a single dose of Fibapo and were killed 6 and $10 \mathrm{~h}$ later. In APAP hepatotoxicity, the critical initial step involves GSH depletion owing to conjugation with NAPQI, the reactive metabolite of APAP. ${ }^{10}$ The principal enzyme in NAPQI formation is cytochrome 2E1 (Cyp2E1). ${ }^{9}$ CYP2E1 expression was unchanged by Fibapo (Figure 2a). Although the early depletion of hepatic GSH was not prevented by Fibapo, GSH contents were restored to control levels by $10 \mathrm{~h}$ (Figure $2 \mathrm{~b}$ ). These observations suggest that Fibapo would not affect APAP metabolism nor the initial phases of APAP toxicity, ${ }^{10}$ but may help the functional recovery of hepatocytes as indicated by GSH levels.

Sustained activation and mitochondrial translocation of c-jun- $N$-terminal protein kinase (JNK), leading to loss of 
a

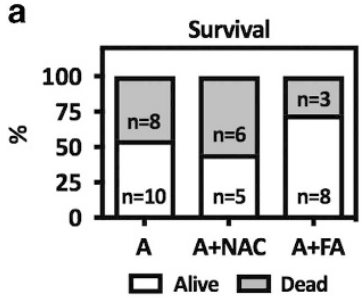

C

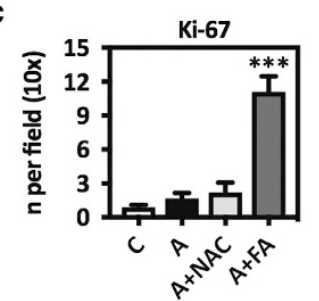

b
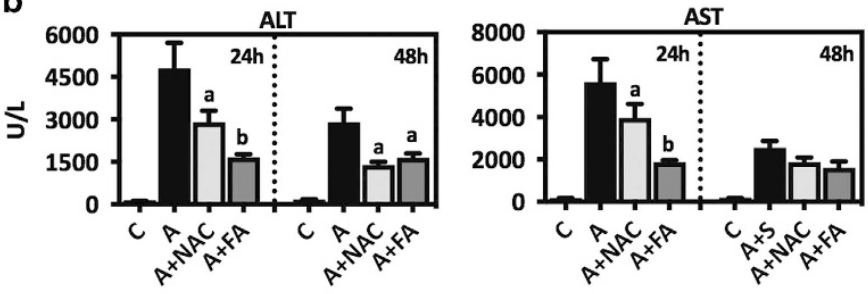

d

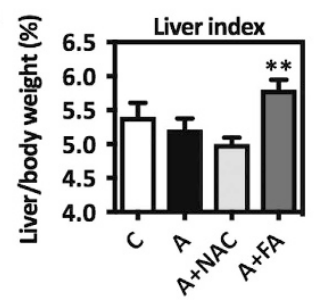

Figure 3 Late administration of Fibapo protects from lethal doses of APAP and stimulates liver regeneration. (a) Mice were treated with APAP (A) (500 mg/kg) and 6 and $24 \mathrm{~h}$ later received two doses of either NAC $(A+N A C)$ or Fibapo $(A+F A)$. Graph shows total mouse survival at $48 \mathrm{~h}$ after APAP intoxication. (b) Serum levels of liver enzymes in mice treated as described and measured at 24 and $48 \mathrm{~h}$ after APAP intoxication. (c) Quantification of hepatocytes with Ki-67-positive nuclei as determined by immunohistochemical analysis performed in liver tissue sections from mice treated as described. Liver tissue samples were obtained from surviving mice $48 \mathrm{~h}$ after APAP administration. (d) Liver weight to body weight ratio (liver index) in mice from the different treatment groups described. This parameter was measured in mice surviving $48 \mathrm{~h}$ after APAP administration. ${ }^{a} P<0.05$ versus $A,{ }^{b} P<0.05$ versus $A+N A C,{ }^{* *} P<0.01$ versus $A+N A C,{ }^{* *} P<0.001$ versus $A+N A C$

mitochondrial potential and ATP production, has been mechanistically related to APAP hepatotoxicity. ${ }^{9,42}$ Consistently, we observed that APAP increased JNK phosphorylation and mitochondrial translocation (Figure 2c). Although at $6 \mathrm{~h}$ post APAP administration p-JNK levels were not affected by Fibapo these were significantly reduced by $10 \mathrm{~h}$ (Figure 2c). Concomitantly, increased activation of extracellular signalregulated kinase 1/2 (ERK1/2), considered part of the compensatory pro-regenerative signaling triggered by APAP toxicity, ${ }^{39,43}$ was observed in Fibapo-treated mice (Figure 2d). Expression of $B c l-x L$, an inhibitor of mitochondrial-dependent cell death involved in hepatoprotection from APAP-induced injury, ${ }^{14,42}$ was enhanced upon Fibapo treatment (Figure 2e).

IL-6 upregulation is detected in APAP-intoxicated mice, and is considered part of the endogenous protective response. ${ }^{41}$ In mice treated with Fibapo hepatic IL-6 expression was markedly potentiated (Figure 2f). Expression of the IL-6related hepatoprotective cytokine IL-22 ${ }^{41}$ was also sustained upon Fibapo treatment (Figure 2f). Induction of IL-6 by FGF19 administration has been recently reported in $d b / d b$ mice. ${ }^{44}$ The cellular source of IL-6 in these animals were liver infiltrating myeloid cells, however the precise mechanism by which FGF19 elicited IL-6 production was not evaluated. ${ }^{44}$ FGF19 signals through FGFR4 and FGFR1 isoform $c$ (FGFR1c), and the coexpression of the membrane protein $\beta$ Klotho (KIb) is absolutely required for effective signaling. ${ }^{45} \mathrm{We}$ examined the expression of these receptors in primary cultured mouse macrophages. Interestingly, we found that these cells expressed FGFR1c and Klb, but not FGFR4 (Figure 2g).

Late administration of Fibapo protects from lethal doses of APAP and stimulates parenchymal regeneration. To better mimic the clinical situation, in which patients are treated at late times after APAP poisoning, mice received Fibapo or $\mathrm{NAC}$ at 6 and $24 \mathrm{~h}$ after APAP. In this case we used $500 \mathrm{mg} / \mathrm{kg}$ of APAP, a dose that causes significant mortality and may compromise the endogenous regenerative response. ${ }^{39}$ Under these conditions NAC treatment did not improve mouse survival, whereas mice receiving Fibapo showed less mortality and lower levels of circulating liver enzymes (Figures $3 a$ and $b$ ). Increased hepatocellular proliferation (Ki-67 labeling) (Figure 3c and Supplementary Figure 4) and liver weight to body weight ratio (Figure $3 d$ ) were also observed.

Fibapo improves liver regeneration in aged mice. We recently reported that Fibapo significantly ameliorates the regeneration of steatotic livers. ${ }^{22}$ Aged mice also show impaired regeneration, so we tested the effect of Fibapo in old mice undergoing $\mathrm{PH}$. Fibapo was administered for 3 consecutive days before resection. As described we observed that liver regrowth post $\mathrm{PH}$ was markedly reduced in old mice, ${ }^{46}$ whereas this response was significantly enhanced by Fibapo (Figures 4a and b). Parenchymal injury, which is exacerbated in aged rodents after $\mathrm{PH}^{46,47}$ was likewise reduced by Fibapo (Figure 4c). Interestingly, the hepatic biosynthetic capacity was also markedly enhanced, as indicated by serum albumin concentrations (Figure 4c). Consistently, upon Fibapo injection we detected increased p-p70S6K levels and a robust activation of S6 phosphorylation, which link FGF19 signaling to protein synthesis in liver cells (Figure 4d). ${ }^{32,40}$

Fibapo treatment corrects biochemical and molecular defects associated with the impairment of liver regeneration in aged mice. Steatosis, commonly found in aged livers, ${ }^{47,48}$ and the presence of steatosis-associated cholestasis $^{22,49}$ are related to impaired regeneration after $\mathrm{PH}^{19,20}$ Accordingly, aged mice had increased levels of 
a

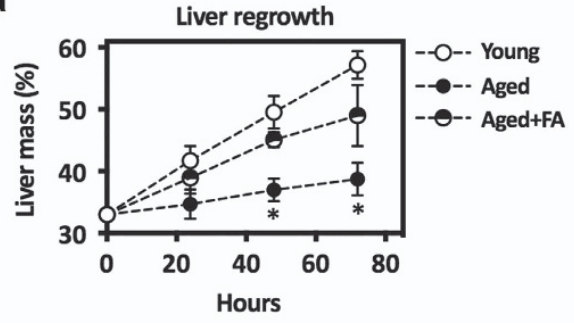

b

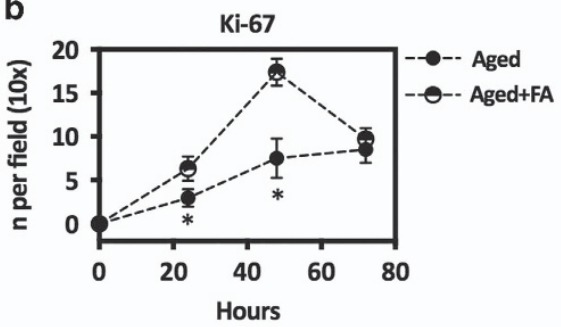

C

ALT
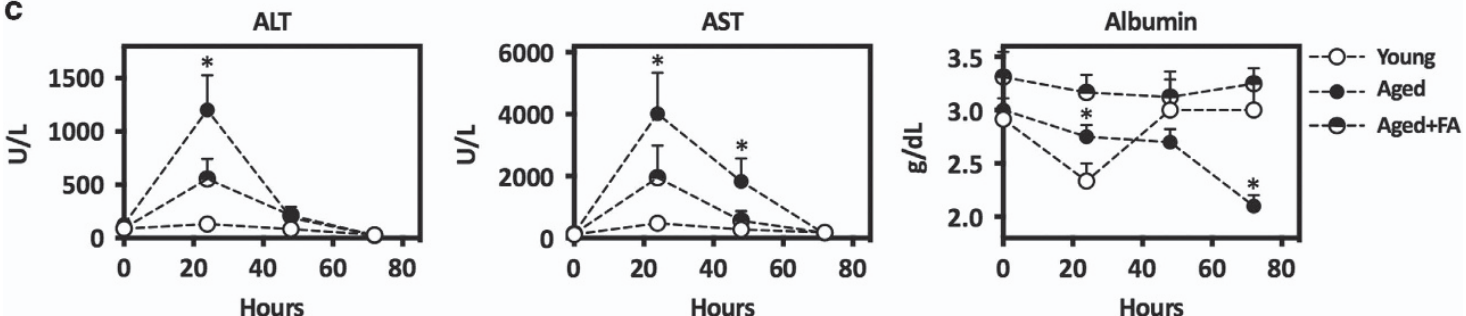

d
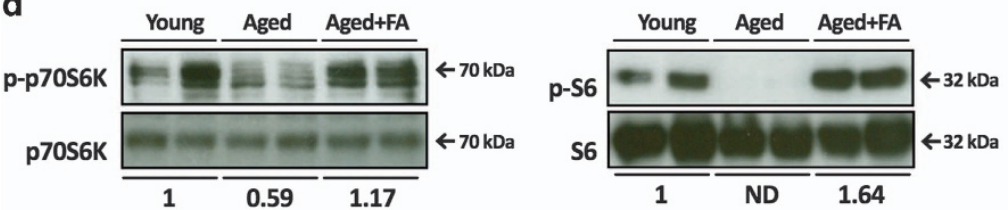

Figure 4 Fibapo improves liver regeneration in aged mice. (a) Recovery of liver mass after $66 \% \mathrm{PH}$ in young mice, aged mice and aged mice that received three injections of Fibapo (FA) on 3 consecutive days before surgery ( $n=6$ mice per group). (b) Quantification of hepatocytes with Ki-67-positive nuclei as determined by immunohistochemical analysis performed in liver tissue sections from aged mice and aged mice treated with Fibapo (FA) at the indicated time points after PH. (c) Circulating levels of liver enzymes and albumin in serum from young mice, aged mice and aged mice treated with Fibapo (FA) measured at the indicated time points after PH. (d) Western blot analysis of phospho-S6 ( $\mathrm{p}$ S6) levels (left panel) and p-p70S6K levels (right panel) in the livers of young mice, aged mice and aged mice treated with Fibapo (FA). Liver samples were analyzed $3 \mathrm{~h}$ after Fibapo administration. Representative blots are shown. ND: not detected. ${ }^{*} P<0.05$ versus aged mice treated with Fibapo

a
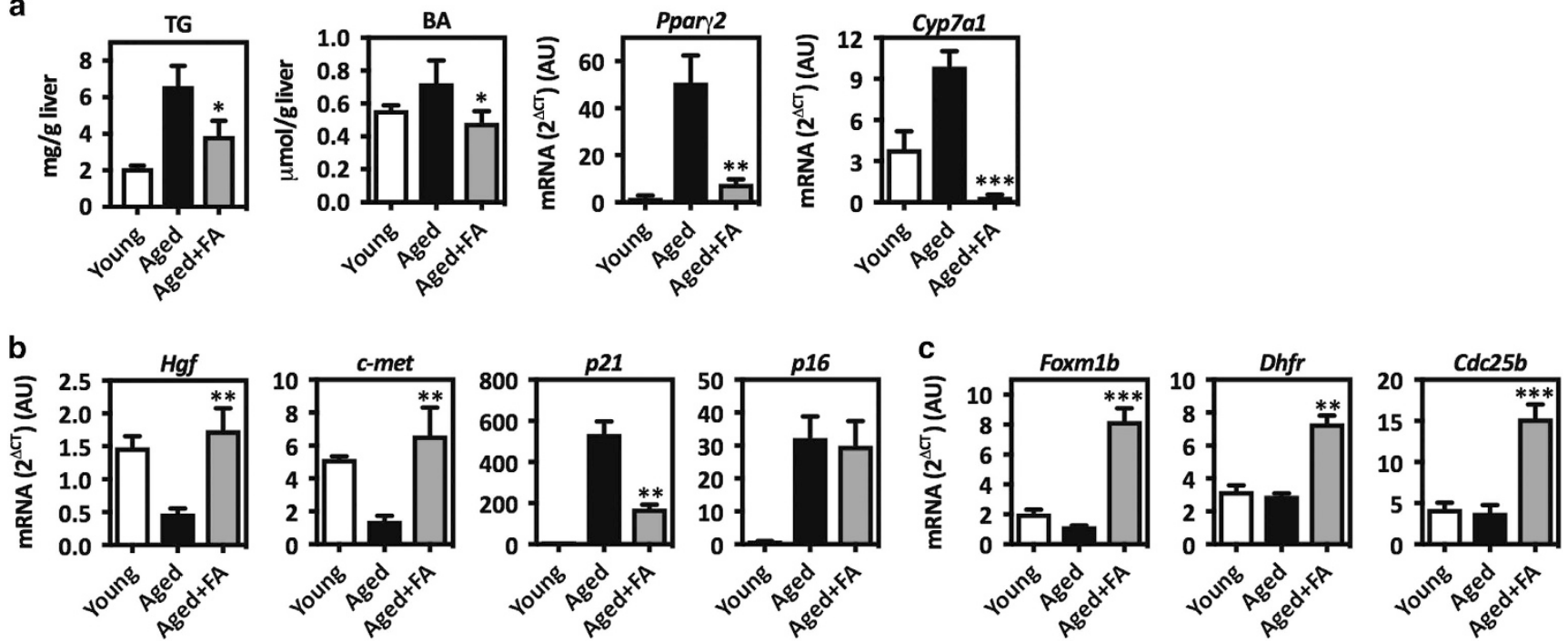

Figure 5 Fibapo improves metabolic parameters and molecular alterations associated with the impairment of liver regeneration in aged mice. (a) Analysis of the intrahepatic levels of triglycerides (TG) and bile acids (BA) in young mice, control aged mice and aged mice that received three injections of Fibapo (FA) on 3 consecutive days before surgery ( $n=6$ mice per group). Quantitative PCR analysis of the levels of Pparg2 and Cyp7a1 mRNAs in the liver of young, aged and aged mice treated as described. (b) Quantitative

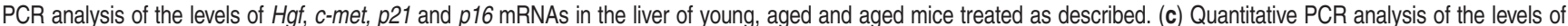
Foxm1b, Dhfr and Cdc25b mRNAs in the liver of young, aged and aged mice treated as described. ${ }^{*} P<0.05,{ }^{* \star} P<0.01$ and ${ }^{* \star *} P<0.001$ versus control aged mice 
a

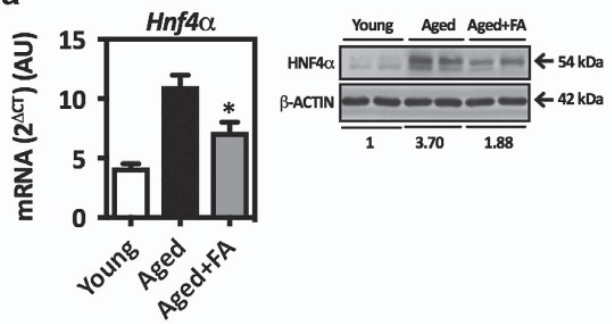

b

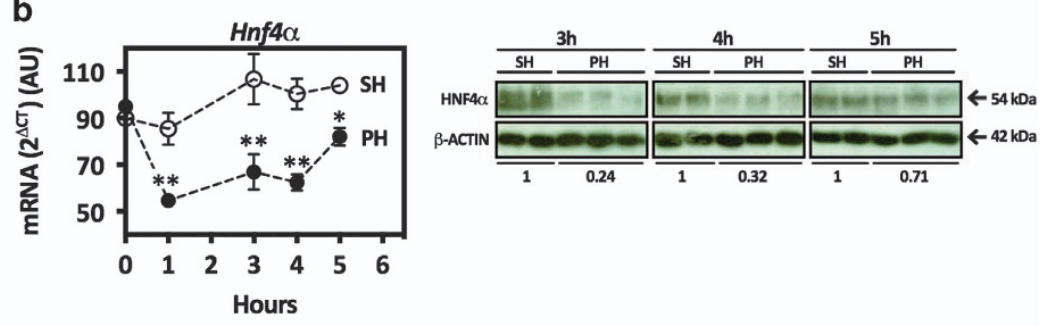

c

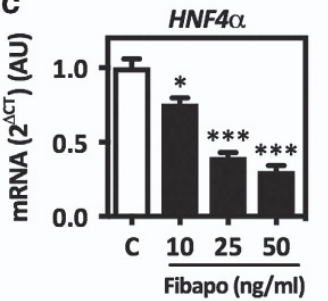

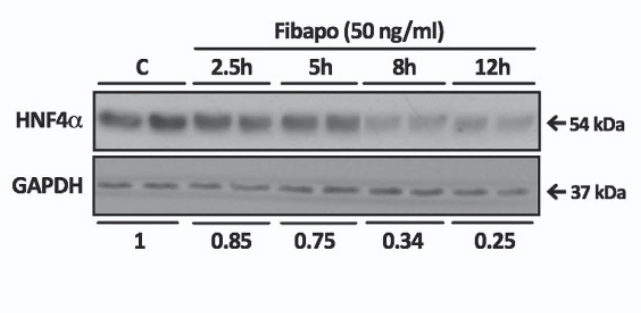

d

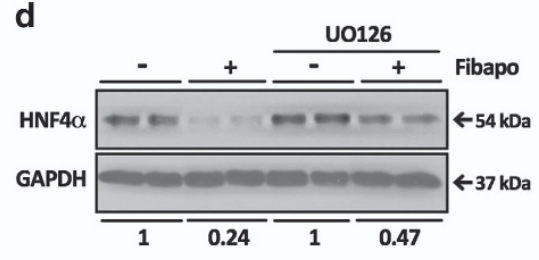

e

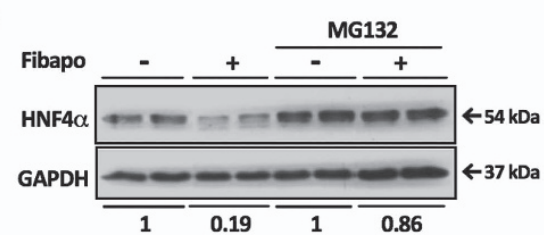

f

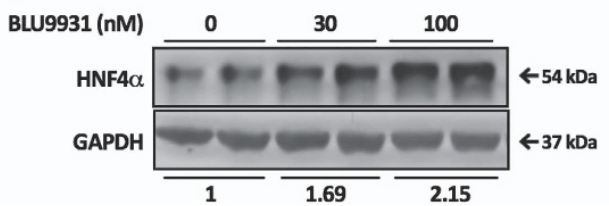

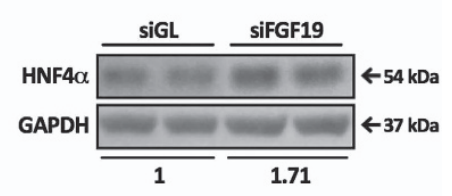

Figure 6 Effect of Fibapo and FGF19/FGFR4 signaling on HNF4 $\alpha$ gene expression. (a) Hnf4 $\alpha$ mRNA and protein levels in the livers of young, aged and aged mice that received three injections of Fibapo (FA) on 3 consecutive days ( $n=6$ mice per group). Hnf4 $\alpha$ mRNA levels were analyzed by quantitative PCR and Hnf4 $\alpha$ protein levels by western blotting. Representative blots are shown. (b) Quantitative PCR analysis of $H n f 4 \alpha$ mRNA and western blot analysis of Hnf4 $\alpha$ protein levels in the liver of young mice at early time points after $\mathrm{PH}$ ( $n=5$ per time point and condition). Liver tissue samples from mice that underwent laparotomy but were not hepatectomized (sham operated mice, SH) are used as controls. Representative blots are shown. (c) Left panel shows HNF4 $\alpha$ mRNA levels analyzed by quantitative PCR in Hep3B cells treated for $12 \mathrm{~h}$ with the indicated concentrations of Fibapo. Right panel shows HNF4 $\alpha$ protein levels determined by western blotting in Hep3B cells treated with $50 \mathrm{ng} / \mathrm{ml}$ of Fibapo for the indicated periods of time. Representative blots are shown. (d) Effect of Fibapo on HNF4 $\alpha$ protein levels in Hep3B cells in the presence of the MEK-ERK signaling inhibitor UO126 analyzed by western blotting. Cells were pre-treated with U0126 (10 $\mu \mathrm{M})$ for $45 \mathrm{~min}$ prior to Fibapo (50 ng/ml) addition and were lysed after $8 \mathrm{~h}$ of treatment. Representative blots are shown. (e) Effect of Fibapo on HNF4 $\alpha$ protein levels in Hep3B cells in the presence of the proteasome inhibitor MG-132. Where indicated cells were pre-treated with MG-132 (10 $\mu$ M) for 45 min and then stimulated with Fibapo for $8 \mathrm{~h}$. Representative blots are shown. (f) Left panel shows the effect of basal FGFR4 signaling on HNF4 $\alpha$ protein levels in Hep3B cells. Cells were treated with the indicated concentrations of the FGFR4-specific inhibitor BLU9931 for $8 \mathrm{~h}$ and HNF4 $\alpha$ protein levels were determined. Right panel shows HNF4 $\alpha$ protein levels in Hep3B cells transfected with an FGF19-specific siRNA (siFGF19) or a control siRNA (siGL) as determined by western blotting $72 \mathrm{~h}$ after transfections. Representative western blots are shown

intrahepatic triglycerides (TG) and total BA compared with young mice (Figure 5a). In agreement with the potent regulatory effects of Fibapo on hepatic lipid and BA metabolism, ${ }^{22,33}$ intrahepatic TG and BA levels were significantly reduced (Figure 5a). Mechanistically, Fibapo inhibited the expression of peroxisome proliferator-activated receptor $\gamma$ variant 2 and cytochrome 7a1 genes, key mediators of hepatic TG accumulation and BA synthesis, respectively ${ }^{50,51}$ (Figure 5a).

Impaired aged liver regeneration has been linked to defective expression of genes involved in growth factor signaling and cell cycle regulation. ${ }^{23,30}$ We observed that the reduced expression of hepatocyte growth factor $(\mathrm{Hgf})$ and its receptor $\mathrm{c}$-met found in the livers of aged mice ${ }^{25,46}$ was reversed by Fibapo (Figure $5 b$ ). As described, we also detected increased mRNA levels of the cell cycle inhibitors p21 and p16 in aged livers. ${ }^{46,52}$ p21 overexpression was significantly corrected by Fibapo, however p16 remained unaltered (Figure $5 \mathrm{~b}$ and Supplementary Figure 5). Among the best-characterized mechanisms involved in the impairment of aged liver regeneration is the transcriptional repression of E2F-dependent genes. ${ }^{23}$ This was shown for key cell proliferation-related genes like Foxm1b and Dhfr. ${ }^{53,54}$ Foxm $1 b$ and Dhfr expression was markedly increased in aged mice treated with Fibapo (Figure 5c). Consistent with the strong induction of Foxm1b expression, Cdc25b, a Cdk phosphatase important for hepatocyte cell cycle progression and a transcriptional target of Foxm1b, ${ }^{55}$ was also induced (Figure $5 \mathrm{c}$ ). Accordingly, the expression of proliferating cell nuclear antigen (PCNA) was also increased (Supplementary Figure 5).

Fibapo regulates hepatocyte nuclear factor $4 a$ (HNF4a) gene expression. HNF4a is a key transcription factor for the preservation of hepatocyte differentiation and quiescence. ${ }^{5}$ HNF4a knockdown in mouse liver results in a strong hepatoproliferative response. ${ }^{56-59}$ Remarkably, it has been recently reported that hepatic expression of $\mathrm{Hnf} 4 a$ is increased in aged rats. ${ }^{60}$ We validated this observation in aged mice, and we also found that Fibapo reduced HNF4a mRNA and protein levels (Figure 6a). HNF4a transcriptional activity is repressed in the first hours after $\mathrm{PH}$, allowing the induction of early genes mediating the onset of liver regeneration. ${ }^{61,62}$ Consequently, we evaluated HNF4a 
expression shortly after $\mathrm{PH}$ and found a transient but significant downregulation of Hnf4a expression during the normal regenerative response in young mice (Figure 6b). These observations suggest that $\mathrm{Hnf} 4 \mathrm{a}$ downregulation may also contribute to the pro-regenerative activity of Fibapo in aged mice livers. The mechanisms regulating the expression of HNF4a in the adult liver are likely to be complex and are not completely known. ${ }^{5}$ Previously, we reported that the splice regulator SLU7 is a fundamental factor in the preservation of hepatocellular differentiation and quiescence, and a positive effector of HNF4a gene expression in mouse liver. ${ }^{63}$ Therefore, we determined SLU7 expression in the livers of young and aged mice, as well as in aged mice treated with Fibapo. As observed for HNF4a we found that SLU7 mRNA levels were higher in the liver of aged mice and were significantly reduced upon Fibapo administration (Supplementary Figure 6a).

Next, we evaluated whether Fibapo could directly regulate HNF4a expression in liver cells. HNF4a mRNA and protein levels were reduced in Hep3B cells upon Fibapo treatment (Figure 6c), and this was partially dependent on mitogen-activated protein kinase kinase (MEK)-ERK signaling (Figure $6 \mathrm{~d}$ and Supplementary Figure 6b). Consistently, FGF19 also reduced HNF4a mRNA and protein levels in Hep3B cells (Supplementary Figure 6c). Interestingly, Fibapo-mediated HNF4a downregulation was to a great extent proteasome dependent (Figure 6e). The specificity of these findings, and the significance of the FGF19/FGFR4 signaling system in the regulation of HNF4a expression, were further supported by the observation that both inhibition of FGFR4 with BLU9931, an FGFR4-specific small molecule inhibitor, ${ }^{64}$ or upon FGF19 knockdown by siRNA transfection, increased basal HNF4a protein levels (Figure $6 f$ and Supplementary Figure 6d).

\section{Discussion}

We evaluated the therapeutic potential of Fibapo, an engineered version of FGF19 with improved pharmacokinetics ${ }^{22}$ in two clinically relevant models of acute liver failure and impaired regeneration. In APAP-induced liver injury, Fibapo reduced parenchymal necrosis and promoted a robust regenerative response. Physiologically, FGF19 expression is induced in ileal enterocytes by BA during their enterohepatic circulation, and FGF15 was recently identified as an important endogenous mediator of mouse liver regeneration and parenchymal protection after $\mathrm{PH} .{ }^{34-36}$ The role of endogenous FGF15/19 in APAP toxicity is unknown. However, inhibition of ileal FGF15 expression by removing BA from the enterohepatic circulation, or its upregulation by feeding mice a cholate-supplemented diet, were, respectively, associated with increased or reduced APAPmediated liver injury. ${ }^{65}$ These findings, together with our current observations of the beneficial effects of Fibapo suggest a cytoprotective and regenerative role for FGF15 in APAP hepatotoxicity. The mechanisms mediating Fibapo hepatoprotection are likely to be diverse. Although it did not inhibit the early depletion of hepatic GSH, recovery of GSH levels was faster in treated mice. Interestingly, a similar effect on GSH levels was observed in APAP-intoxicated mice treated with vascular endothelial growth factor. ${ }^{15}$ In the case of Fibapo, this may reflect an improvement of the overall hepatic metabolic capacities, which would be in agreement with the strong positive effects of FGF19 on nutrient metabolism, protein synthesis and hepatocellular energetics. $^{32,40}$ In support of this notion we observed increased p70S6K phosphorylation in Fibapo-treated mice. Activation of the mTORC1-p70S6K pathway by FGF19 in the liver has been recently reported. ${ }^{22,40}$ This pathway mediates robust anabolic effects, including the stimulation of cell growth and proliferation. ${ }^{66}$ Besides p70S6K, we also detected enhanced activation of ERK1/2, a kinase strongly linked to hepatocyte proliferation. ${ }^{32,67}$ Interestingly Fibapo increased the expression of Foxm1b, a transcription factor essential for hepatocyte proliferation but also associated with hepatocellular hypertrophy. ${ }^{55,68}$ Accordingly, we observed a hyperproliferative and a hypertrophic response in mice that received Fibapo after APAP intoxication. These combined effects may be mechanistically relevant, as liver growth and regeneration are emerging as key determinants of the outcome of APAP intoxication. Consistently, it has been recently shown that inhibition of epidermal growth factor receptor, a key mediator of liver regeneration after $\mathrm{PH},{ }^{69}$ results in impaired regeneration, exacerbated liver injury and high mortality in APAP intoxication. ${ }^{70}$

The pro-regenerative effects of Fibapo were accompanied by reduced parenchymal injury. Prolongued translocation of active JNK to mitochondria is a central event in APAP-induced hepatocellular death. ${ }^{9,42}$ We observed reduced activation of mitochondrial JNK upon Fibapo administration. The mechanisms involved in this response are currently unknown. JNK activation during APAP-mediated liver injury is strongly related to mitochondrial stress and production of reactive oxygen species. ${ }^{10,42}$ We could speculate that enhanced recovery of GSH levels by Fibapo could reduce oxidative stress, attenuate JNK activation and therefore limit its mitochondrial translocation. ${ }^{42}$ Nevertheless, further studies are required to delineate the precise mechanisms of this response. Upregulation of Bcl-xL may also contribute to the protective effects of Fibapo, as $\mathrm{BCl}-\mathrm{XL}$ has been linked to the hepatoprotective activity of stem cell factor and c-kit in APAP-induced liver injury. ${ }^{14}$

The activation of the innate immune system upon APAP intoxication is increasingly regarded as part of an endogenous protective reaction. ${ }^{9}$ In particular, IL-6 expression appears necessary for liver regeneration. ${ }^{71}$ Intriguingly, we observed that Fibapo administration to APAP-treated mice markedly enhanced IL- 6 expression. This suggests that Fibapo could also promote liver regeneration through non-cell autonomous pathways. Our findings are consistent with a recent report showing hepatic IL-6 upregulation upon FGF19 administration to $d b / d b$ mice. ${ }^{44}$ In that study the source of FGF19-triggered IL-6 were liver infiltrating myeloid cells, although the exact mechanism of FGF19-mediated IL-6 induction was not examined. ${ }^{44}$ In view of these and our current observations, we evaluated the expression of the FGF19 receptors FGFR4, FGFR1c and the obligate co-receptor $\mathrm{Klb}^{45}$ in murine macrophages. We found that mouse macrophages express FGFR1c and $\mathrm{Klb}$, but not FGFR4 mRNA. To our knowledge, this is the first description of the expression of these receptors in murine innate immune cells, and it suggests that the cellular targets of FGF19, and Fibapo, might be broader than initially thought.

We also demonstrated the therapeutic potential of Fibapo in the context of aged liver regeneration. Interestingly, basal circulating FGF19 levels are lower in older individuals 
compared with young healthy people. ${ }^{72}$ Given the important regulatory role of FGF19 in liver fat metabolism, ${ }^{22,33}$ its reduced availability in older persons may underlie the steatosis commonly found in this population. ${ }^{4,48}$ Steatosis represents a significant obstacle to a successful liver regeneration. ${ }^{19,20}$ Its attenuation by Fibapo may explain in part the decreased injury and improved liver regeneration found in aged mice. Nevertheless, we believe that this molecule has also more direct actions on genes involved in hepatocellular proliferation. Restoration of $\mathrm{Hgf}$ and $\mathrm{c}$-met expression levels, which are depressed in aged livers, ${ }^{25,46}$ may be an important effect of Fibapo given the crucial role of the HGF/c-Met system in liver regeneration. ${ }^{69}$

One important molecular barrier in the regeneration of aged livers is the formation of repressive complexes on E2Fdependent promoters, such as those of Foxm $1 \mathrm{~b}$ and $\mathrm{Dhfr}$ genes, which are essential for cell proliferation. ${ }^{23} \mathrm{We}$ observed that Fibapo administration induced a robust upregulation of Foxm1B and Dhfr. Stimulation of Foxm $1 b$ expression by Fibapo may be a key mechanism of action. Certainly, forced hepatic expression of Foxm $1 b$, either from a transgene or an adenoviral vector, improves liver regeneration in old mice, ${ }^{30,73}$ and the beneficial effects of growth hormone and farnesoid $X$ receptor agonists on aged mouse liver regeneration have been related to Foxm $1 b$ upregulation. ${ }^{26,31,53}$ Moreover, the inhibition of $p 21$ and the activation of $C d c 25 b$ gene expression elicited by Fibapo may be also dependent on Foxm $1 b$ stimulation. ${ }^{55}$ Concomitant with the upregulation of Foxm $1 b$ we found that Fibapo also reduced the levels of HNF4a, a key factor in the preservation of hepatocellular differentiation and quiescence. ${ }^{5,56,58}$ The increased expression of HNF4a recently found in aged livers, ${ }^{60}$ and confirmed by us, could certainly pose a barrier to liver regeneration in old animals. Indeed, recent studies have shown that shortly after $\mathrm{PH}$ there is a reduction in the transcriptional regulatory activity of HNF4a in the liver of young mice. ${ }^{61,62}$ Although this decrease in HNF4a activity may be due to its physical redistribution on the genome, as occurs during liver development, ${ }^{74}$ we observed a transient but clear downregulation of HNF4a gene expression in the first hours post $\mathrm{PH}$. This previously unrecognized response may be part of the molecular mechanisms allowing the entry of otherwise quiescent hepatocytes into the cell cycle.

The mechanisms responsible for HNF4a upregulation in aged mouse livers are likely to be multifarious. For instance, tissue hypoxia, a condition that develops in the liver of old animals, has been reported to stimulate HNF4a expression in hepatocytes. ${ }^{60}$ Now we found that the levels of SLU7, a gene that promotes HNF4a expression in the adult liver, ${ }^{63}$ were increased in the liver of aged mice and interestingly were downregulated upon Fibapo administration. It is worth mentioning that SLU7 expression is also rapidly reduced in mouse liver shortly after $\mathrm{PH},{ }^{63}$ with kinetics overlapping those of HNF4a expression reported here.

Although the identity of the endogenous signals mediating HNF4a downregulation after PH is currently unknown, we could induce this effect in the liver of aged mice by Fibapo treatment. Our in vitro experiments proved that Fibapo can directly regulate $\mathrm{HNF} 4 a$ gene expression, both at the transcriptional and post-transcriptional level, promoting HNF4a proteasomal degradation. These findings are consistent with the previously described inhibition of HNF4a gene expression upon pharmacological activation of the MEK-ERK pathway in liver parenchymal cells. ${ }^{75}$ Interestingly, we also observed that interference with autocrine FGF19/FGFR4 signaling in Hep3B cells increased HNF4a expression. This response supports the specificity of Fibapo effects. However, it may also have broader implications in the context of hepatocarcinogenesis, where HNF4a expression is consistently downregulated and FGF19 is frequently overexpressed. ${ }^{5,76}$

Collectively, our observations demonstrate the efficacy of FGF19-based molecules like Fibapo as hepatoprotective and pro-regenerative agents. The two experimental models implemented in this study reproduce clinical situations for which effective treatments are lacking. The validation of these findings in models of acute liver injury and regeneration using larger animals is therefore warranted.

\section{Materials and Methods}

Animal models. All the experimental protocols were approved and performed according to the guidelines of the Animal Care Committee of the University of Navarra. For APAP treatment mice (C57/BL/6 J, male 8-12 weeks of age) were injected intraperitoneally with $300 \mathrm{mg} / \mathrm{kg}$ or $500 \mathrm{mg} / \mathrm{kg}$ of the compound after an overnight fast. APAP (Sigma-Aldrich, St. Louis, MO, USA) was dissolved in warm PBS $\left(55^{\circ} \mathrm{C}\right)$ and cooled to $37^{\circ}$ before injection, as described. ${ }^{77}$ When indicated mice were killed and livers were removed to be paraffin-embedded or snap frozen in liquid $\mathrm{N}_{2}$. Two-thirds $\mathrm{PH}$ was performed in young (8-12 weeks of age) and old (12-14 months old) C57/BL/6 J male mice as previosuly described. ${ }^{34}$ In the APAP model, and at the indicated time points for each experiment, mice received an intravenous injection of Fibapo $(2 \mathrm{mg} / \mathrm{kg})$, synthesized upon request by GenScript (Piscataway, NJ, USA), ${ }^{22}$ an intraperitoneal injection of NAC (600 mg/kg) (SigmaAldrich), or the same volume of saline $(300 \mu \mathrm{l})$. Aged C57/BL/6 J male mice received a daily single subcutaneous injection of Fibapo $(2 \mathrm{mg} / \mathrm{kg})$ or saline for three days prior to $\mathrm{PH}$. Hepatectomies were performed $24 \mathrm{~h}$ after the last injection as previously described. ${ }^{22}$ For the analysis of liver, S6 and p70S6K phosphorylation Fibapo (2 mg/kg) was injected intravenously to mice that had been fasted overnight.

Cell culture and treatments. The human hepatocarcinoma cell line Hep3B (from ATCC) was cultured as described. ${ }^{63}$ Cells were treated with Fibapo in serum-free DMEM medium supplemented with $0.2 \%$ bovine serum albumin. Where indicated cells were pre-treated with the MEK1 inhibitor U0126 $(10 \mu \mathrm{M})$ (Promega, Madison, WI, USA), the proteasome inhibitor MG-132 (10 $\mu \mathrm{M})$ (Sigma-Aldrich), or the specific FGFR4 inhibitor BLU9931 (100 nM) (Cayman Chemical, Ann Arbor, MI, USA). ${ }^{64}$ For FGF19 knockdown Hep3B cells were transfected with FGF19-specific siRNAs (Santa Cruz Biotechnology, Santa Cruz, CA, USA), or with control siRNAs (siGL) for $48 \mathrm{~h}$ as previously described. ${ }^{63}$ Experiments were performed at least three times in duplicates. Bone marrow-derived macrophages were prepared essentially as described. ${ }^{78}$ To $_{0}$ induce the proliferation of macrophages, bone marrow cells were plated in plastic plates with $10 \%$ fetal calf serum in RPMl1640 supplemented with $100 \mathrm{ng} / \mathrm{ml}$ recombinant murine macrophage-colony stimulating factor (R\&D Systems, Minneapolis, MN, USA).

Western blot analyses. Cells and liver tissues were lysed in RIPA buffer and homogenates were subjected to Western blot analysis as reported. ${ }^{34,63}$ Liver tissue mitochondria were isolated as described before. ${ }^{79}$ Antibodies used were: anti-p-ERK1/2 (Thr202, Tyr204), anti-ERK1/2, anti-p-JNK (Thr183, Tyr185), anti-p-p70S6K (Thr389), anti-p70S6K, anti-p-S6 (Ser235, Ser236), anti-S6, anti- $\beta$-actin and anti-GAPDH (both used as loading controls) from Cell Signaling Technology (Beverly, MA, USA); anti- $\alpha$ tubulin, anti-CCNE1, anti-PCNA, anti-p21 and rabbit polyclonal anti-HNF4 $\alpha(\mathrm{H}-171)$ were from Santa Cruz Biotechnology (Dallas, TX, USA); mouse monoclonal anti-HNF4 $\alpha$ (PP-K9218-00) was from Perseus Proteomics Inc. (Tokyo, Japan); anti-CYP2E1 and anti-cytochrome oxidase IV were from Abcam (Cambridge, UK). Numbers shown under blot images indicate the quantification of bands intensity (averaged values) relative to controls, which were arbitrarily given the value of one.

RNA isolation and qPCR. Total RNA from liver tissues and Hep3B cells was extracted using the automated Maxwell system from Promega. Reverse 
transcription was performed as described. ${ }^{63}$ Real-time PCRs were performed with iQ SYBR Green supermix (BioRad, Hercules, CA, USA) in a CFX96 system from BioRad as previously described. ${ }^{63}$ Primers are described in Supplementary Table 1.

Hepatic triglyceride content determination. Intrahepatic TG concentration was measured by saponification in ethanolic $\mathrm{KOH}$ and determining triolein equivalents using a commercially available kit (BQ029A-CR, BQ Kits, San Diego, CA, USA) as described. ${ }^{22}$

Histological determinations. Liver tissue samples were formalin-fixed and paraffin-embedded. Ki-67 immunostaining was performed as described. ${ }^{22}$ Positive Ki-67 hepatocyte number was determined in 10 liver fields per mice $(x 10$ amplification) using ImageJ software (NIH, Bethesda, MD, USA). To evaluate the degree of tissue necrosis H\&E staining was performed and scored as previously reported. ${ }^{34}$ Hepatocyte cell size was determined after $\beta$-catenin immunostaining of paraffin sections to outline individual hepatocytes, anti- $\beta$-catenin antibody was from Cell Signaling Technology. To calculate hepatocyte cell size 10 fields $(x 40)$ per tissue sample were analyzed as we previosuly described. ${ }^{80} \mathrm{GSH}$ contents in liver tissues were determined as reported. ${ }^{77}$ For the determination of hepatic levels of BA liver tissues were homogenated in water $(5 \mathrm{mg} / 500 \mu \mathrm{l})$, sonicated and centrifuged at $10000 \times \mathrm{g}$ for $10 \mathrm{~min}$. BAs concentrations were determined in supernatants by an enzymatic/colorimetric method using a commercially available kit (Randox Laboratories, Crumlin, UK) as reported. ${ }^{22}$

Serum biochemistry. Serum levels of alanine aminotransferase, aspartate aminotransferase, lactate dehydrogenase and albumin were measured as previously reported. $22,34,63$

Statistical analysis. Data are means \pm S.E.M. Data were compared using the Student $t$-test. A $P$-value of $<0.05$ was considered significant. Data analyses were performed using GraphPad Prism software (GraphPad Software Inc., San Diego, USA) version 7.0 was employed for statistical analyses.

\section{Conflict of Interest}

The authors declare no conflict of interest.

Acknowledgements. Work in the authors' laboratory is supported by CIBERehd and Grants from Instituto de Salud Carlos III (ISCIII) co-financed by 'Fondo Europeo de Desarrollo Regional' (FEDER) 'Una manera de hacer Europa', numbers: FIS PI13/00359, Pl13/00385 and Pl16/01126. Grants SAF2015-66515-R, SAF201569944-R, SAF 2016-75972 R from Ministerio de Economía y Competitividad, and the center grant P50AA011999 funded by NIAAA. 'Ramón y Cajal-I3' contract to MUL, Mineco-FPI Fellowship to MB-V. Marie Curie EU contract to MGF-B. Fundación M Torres; Fundación Eugenio Rodríguez Pascual; Fundación Mario Losantos; Fundación Familia Puig-Infante and Fundación Bancaria La CaixaHepacare Project. The technical support of Mr Roberto Barbero and Laura Guembe is acknowledged. The generous support of Mr Eduardo Avila and Mr Sergio Durá is highly appreciated.

\section{Publisher's Note}

Springer Nature remains neutral with regard to jurisdictional claims in published maps and institutional affiliations.

1. Michalopoulos GK. Advances in liver regeneration. Expert Rev Gastroenterol Hepatol 2014; 8: 897-907.

2. Fausto N, Campbell JS, Riehle KJ. Liver regeneration. Hepatology 2006; 43: S45-S53.

3. Pomfret EA, Pomposelli JJ, Gordon FD, Erbay N, Lyn Price L, Lewis WD et al. Liver regeneration and surgical outcome in donors of right-lobe liver grafts. Transplantation 2003; 76: 5-10.

4. Avila MA. Long distance calling for liver regeneration: identification of neuroendocrine signalling pathways activated after partial hepatectomy. J Hepatol 2011; 54: 403-405.

5. Berasain C, Avila MA. Regulation of hepatocyte identity and quiescence. Cell Mol Life Sci 2015; 72: 3831-3851.

6. Michalopoulos GK. Hepatostat: liver regeneration and normal liver tissue maintenance. Hepatology 2016; 65: 1384-1392.

7. Forbes SJ, Newsome PN. Liver regeneration - mechanisms and models to clinical application. Nat Rev Gastroenterol Hepatol 2016; 13: 473-485.

8. Bernal W, Lee WM, Wendon J, Larsen FS, Williams R. Acute liver failure: a curable disease by 2024? J Hepatol 2015; 62: S112-S120.
9. Jaeschke $\mathrm{H}$, Williams $\mathrm{CD}$, Ramachandran $\mathrm{A}$, Bajt ML. Acetaminophen hepatotoxicity and repair: the role of sterile inflammation and innate immunity. Liver Int 2012; 32: 8-20.

10. Du K, Ramachandran A, Jaeschke H. Oxidative stress during acetaminophen hepatotoxicity: Sources, pathophysiological role and therapeutic potential. Redox Biol 2016; 10: 148-156.

11. Schmidt LE, Dalhoff K. Alpha-fetoprotein is a predictor of outcome in acetaminopheninduced liver injury. Hepatology 2005; 41: 26-31.

12. Apte U, Singh S, Zeng G, Cieply B, Virji MA, Wu T et al. Beta-catenin activation promotes liver regeneration after acetaminophen-induced injury. Am J Pathol 2009; 175: 1056-1065.

13. Rudraiah S, Manautou JE. From hepatoprotection models to new therapeutic modalities for treating liver diseases: a personal perspective. F1000Res 2016; 5(F1000 Faculty Rev): 1698.

14. Hu B, Colletti LM. Stem cell factor and c-kit are involved in hepatic recovery after acetaminophen-induced liver injury in mice. Am J Physiol Gastrointest Liver Physiol 2008; 295: G45-G53.

15. Donahower BC, McCullough SS, Hennings L, Simpson PM, Stowe CD, Saad AG et al. Human recombinant vascular endothelial growth factor reduces necrosis and enhances hepatocyte regeneration in a mouse model of acetaminophen toxicity. J Pharmacol Exp Ther 2010; 334: 33-43.

16. Ye D, Wang Y, Li H, Jia W, Man K, Lo CM et al. Fibroblast growth factor 21 protects against acetaminophen-induced hepatotoxicity by potentiating peroxisome proliferator-activated receptor coactivator protein-1 $\alpha$-mediated antioxidant capacity in mice. Hepatology 2014; 60: 977-989.

17. Stutchfield BM, Antoine DJ, Mackinnon AC, Gow DJ, Bain CC, Hawley CA et al. CSF1 restores innate immunity after liver injury in mice and serum levels indicate outcomes of patients with acute liver failure. Gastroenterology 2015; 149 1896-1909 e14.

18. Scheiermann P, Bachmann M, Goren I, Zwissler B, Pfeilschifter J, Mühl H. Application of interleukin-22 mediates protection in experimental acetaminophen-induced acute liver injury. Am J Pathol 2013; 182: 1107-1113.

19. Cho JY, Suh K-S, Lee HW, Cho E-H, Yang SH, Cho YB et al. Hepatic steatosis is associated with intrahepatic cholestasis and transient hyperbilirubinemia during regeneration after living donor liver transplantation. Transpl Int 2006; 19: 807-813.

20. Kele PG, van der Jagt EJ, Gouw ASH, Lisman T, Porte RJ, de Boer MT. The impact of hepatic steatosis on liver regeneration after partial hepatectomy. Liver Int 2013; 33: 469-475.

21. Hamano M, Ezaki H, Kiso S, Furuta K, Egawa M, Kizu T et al. Lipid overloading during liver regeneration causes delayed hepatocyte DNA replication by increasing ER stress in mice with simple hepatic steatosis. J Gastroenterol 2014; 49: 305-316.

22. Alvarez-Sola G, Uriarte I, Latasa MU, Fernández-Barrena MG, Urtasun R, Elizalde M et al. Fibroblast growth factor 15/19 (FGF15/19) protects from diet-induced hepatic steatosis: development of an FGF19-based chimeric molecule to promote fatty liver regeneration. Gut 2017; 66: 1818-1828.

23. Timchenko NA. Aging and liver regeneration. Trends Endocrinol Metab 2009; 20: 171-176.

24. Schmucker DL, Sanchez H. Liver regeneration and aging: a current perspective. Curr Gerontol Geriatr Res 2011; 2011: 526379.

25. Zhu C, Ikemoto T, Utsunomiya T, Yamada S, Morine Y, Imura S et al. Senescence-related genes possibly responsible for poor liver regeneration after hepatectomy in elderly patients. $J$ Gastroenterol Hepatol 2014; 29: 1102-1108.

26. Krupczak-Hollis K, Wang X, Dennewitz MB, Costa RH. Growth hormone stimulates proliferation of old-aged regenerating liver through forkhead box m1b. Hepatology 2003; 38: 1552-1562.

27. Jin J, Wang G-L, Shi X, Darlington GJ, Timchenko NA. The age-associated decline of glycogen synthase kinase 3 beta plays a critical role in the inhibition of liver regeneration. Mol Cell Biol 2009; 29: 3867-3880.

28. Jin J, lakova P, Jiang Y, Medrano EE, Timchenko NA. The reduction of SIRT1 in livers of old mice leads to impaired body homeostasis and to inhibition of liver proliferation. Hepatology 2011; 54: 989-998.

29. Loforese G, Malinka T, Keogh A, Baier F, Simillion C, Montani M et al. Impaired liver regeneration in aged mice can be rescued by silencing Hippo core kinases MST1 and MST2 EMBO Mol Med 2017; 9: 46-60.

30. Wang X, Quail E, Hung NJ, Tan Y, Ye H, Costa RH. Increased levels of forkhead box M1B transcription factor in transgenic mouse hepatocytes prevent age-related proliferation defects in regenerating liver. Proc Natl Acad Sci USA 2001; 98: 11468-11473.

31. Chen W-D, Wang Y-D, Zhang L, Shiah S, Wang M, Yang F et al. Farnesoid X receptor alleviates age-related proliferation defects in regenerating mouse livers by activating forkhead box m1b transcription. Hepatology 2010; 51: 953-962.

32. Kir S, Beddow SA, Samuel VT, Miller P, Previs SF, Suino-Powell K et al. FGF19 as a postprandial, insulin-independent activator of hepatic protein and glycogen synthesis. Science 2011; 331: 1621-1624.

33. Potthoff MJ, Kliewer SA, Mangelsdorf DJ. Endocrine fibroblast growth factors $15 / 19$ and 21 : from feast to famine. Genes Dev 2012; 26: 312-324.

34. Uriarte I, Fernández-Barrena MG, Monte MJ, Latasa MU, Chang HCY, Carotti S et al. Identification of fibroblast growth factor 15 as a novel mediator of liver regeneration and its application in the prevention of post-resection liver failure in mice. Gut 2013; 62: 899-910.

35. Kong B, Huang J, Zhu Y, Li G, Williams J, Shen S et al. Fibroblast growth factor 15 deficiency impairs liver regeneration in mice. Am J Physiol Gastrointest Liver Physiol 2014; 306: G893-G902.

36. Padrissa-Altés S, Bachofner M, Bogorad RL, Pohlmeier L, Rossolini T, Böhm F et al. Control of hepatocyte proliferation and survival by Fgf receptors is essential for liver regeneration in mice. Gut 2015; 64: 1444-1453.

37. Modica S, Petruzzelli M, Bellafante E, Murzilli S, Salvatore L, Celli N et al. Selective activation of nuclear bile acid receptor FXR in the intestine protects mice against cholestasis. Gastroenterology 2012; 142 355-65 e1-e4. 
38. Luo J, Ko B, Elliott M, Zhou M, Lindhout DA, Phung $V$ et al. A nontumorigenic variant of FGF19 treats cholestatic liver diseases. Sci Transl Med 2014; 6: 247ra100.

39. Bhushan B, Walesky C, Manley M, Gallagher T, Borude P, Edwards G et al. Proregenerative signaling after acetaminophen-induced acute liver injury in mice identified using a novel incremental dose model. Am J Pathol 2014; 184: 3013-3025.

40. Wan ZY, Tian JS, Tan HWS, Chow AL, Sim AYL, Ban KHK et al. Mechanistic target of rapamycin complex 1 (mTORC1) is an essential mediator of metabolic and mitogenic effects of FGF19 in hepatoma cells. Hepatology 2016; 64: 1289-1301.

41. Mühl H. STAT3, a key parameter of cytokine-driven tissue protection during sterile inflammation - the case of experimental acetaminophen (paracetamol)-induced liver damage. Front Immunol 2016; 7: 163.

42. Hanawa N, Shinohara M, Saberi B, Gaarde WA, Han D, Kaplowitz N. Role of JNK translocation to mitochondria leading to inhibition of mitochondria bioenergetics in acetaminophen-induced liver injury. J Biol Chem 2008; 283: 13565-13577.

43. Furuta K, Yoshida Y, Ogura S, Kurahashi T, Kizu T, Maeda S et al. Gab1 adaptor protein acts as a gatekeeper to balance hepatocyte death and proliferation during acetaminopheninduced liver injury in mice. Hepatology 2016; 63: 1340-1355.

44. Zhou M, Yang H, Learned RM, Tian H, Ling L. Non-cell-autonomous activation of IL-6/STAT3 signaling mediates FGF19-driven hepatocarcinogenesis. Nat Commun 2017; 8: 15433.

45. Kurosu H, Choi M, Ogawa Y, Dickson AS, Goetz R, Eliseenkova AV et al. Tissue-specific expression of betaKlotho and fibroblast growth factor (FGF) receptor isoforms determines metabolic activity of FGF19 and FGF21. J Biol Chem 2007; 282: 26687-26695.

46. Enkhbold $\mathrm{C}$, Morine $\mathrm{Y}$, Utsunomiya $\mathrm{T}$, Imura $\mathrm{S}$, Ikemoto $\mathrm{T}$, Arakawa $\mathrm{Y}$ et al. Dysfunction of liver regeneration in aged liver after partial hepatectomy. J Gastroenterol Hepatol 2015; 30: 1217-1224.

47. Sánchez-Hidalgo JM, Naranjo A, Ciria R, Ranchal I, Aguilar-Melero P. Ferrín G et al. Impact of age on liver regeneration response to injury after partial hepatectomy in a rat model. $J$ Surg Res 2012; 175: e1-e9.

48. Hartleb M, Barański K, Zejda J, Chudek J, Wieccek A. Non-alcoholic fatty liver (NAFL) and advanced fibrosis in the elderly: results from a community-based Polish survey. Liver Int 2017. (e-pub ahead of print).

49. Bechmann LP, Kocabayoglu P, Sowa J-P, Sydor S, Best J, Schlattjan M et al. Free fatty acids repress small heterodimer partner (SHP) activation and adiponectin counteracts bile acidinduced liver injury in superobese patients with nonalcoholic steatohepatitis. Hepatology 2013; 57: 1394-1406

50. Chiang JYL. Bile acids: regulation of synthesis. J Lipid Res 2009; 50: 1955-1966.

51. Lee YJ, Ko EH, Kim JE, Kim E, Lee H, Choi H et al. Nuclear receptor PPAR $\gamma$-regulated monoacylglycerol O-acyltransferase 1 (MGAT1) expression is responsible for the lipid accumulation in diet-induced hepatic steatosis. Proc Natl Acad Sci USA 2012; 109 : 13656-13661.

52. Wang M-J, Chen F, Li J-X, Liu C-C, Zhang H-B, Xia Y et al. Reversal of hepatocyte senescence after continuous in vivo cell proliferation. Hepatology 2014; 60: 349-361.

53. Wang G-L, Shi X, Salisbury E, Sun Y, Albrecht JH, Smith RG et al. Growth hormone corrects proliferation and transcription of phosphoenolpyruvate carboxykinase in livers of old mice via elimination of CCAAT/enhancer-binding protein alpha-Brm complex. J Biol Chem 2007; 282 1468-1478.

54. lakova $\mathrm{P}$, Awad SS, Timchenko NA. Aging reduces proliferative capacities of liver by switching pathways of C/EBPalpha growth arrest. Cell 2003; 113: 495-506.

55. Wang X, Kiyokawa H, Dennewitz MB, Costa RH. The Forkhead Box m1b transcription factor is essential for hepatocyte DNA replication and mitosis during mouse liver regeneration. Proc Natl Acad Sci USA 2002; 99: 16881-16886.

56. Walesky C, Gunewardena S, Terwilliger EF, Edwards G, Borude P, Apte U. Hepatocytespecific deletion of hepatocyte nuclear factor- $4 \alpha$ in adult mice results in increased hepatocyte proliferation. Am J Physiol Gastrointest Liver Physiol 2013; 304: G26-G37.

57. Walesky C, Edwards G, Borude P, Gunewardena S, O'Neil M, Yoo B et al. Hepatocyte nuclear factor 4 alpha deletion promotes diethylnitrosamine-induced hepatocellular carcinoma in rodents. Hepatology 2013; 57: 2480-2490.

58. Bonzo JA, Ferry CH, Matsubara T, Kim J-H, Gonzalez FJ. Suppression of hepatocyte proliferation by hepatocyte nuclear factor $4 \alpha$ in adult mice. J Biol Chem 2012; 287: 7345-7356.

59. Walesky C, Apte U. Role of hepatocyte nuclear factor $4 \alpha(\mathrm{HNF} 4 \alpha)$ in cell proliferation and cancer. Gene Expr 2015; 16: 101-108.

60. Park EY, Lee CH, Lee EK, Kim JH, Cova A, Lee SK et al. HNF4 $\alpha$ contributes to glucose formation in aged rat hepatocytes. Exp Gerontol 2013; 48: 1518-1525.

61. Chen H, Lu S, Zhou J, Bai Z, Fu H, Xu X et al. An integrated approach for the identification of USF1-centered transcriptional regulatory networks during liver regeneration. Biochim Biophys Acta 2014; 1839: 415-423.

62. Jiao H, Zhu Y, Lu S, Zheng Y, Chen H. An integrated approach for the identification of HNF $4 \alpha$-centered transcriptional regulatory networks during early liver regeneration. Cell Physiol Biochem 2015; 36: 2317-2326.
63. Elizalde M, Urtasun R, Azkona M, Latasa MU, Goñi S, Garcia-Irigoyen $O$ et al. Splicing regulator SLU7 is essential for maintaining liver homeostasis. J Clin Invest 2014; 124: 2909-2920.

64. Hagel M, Miduturu C, Sheets M, Rubin N, Weng W, Stransky N et al. First selective small molecule inhibitor of FGFR4 for the treatment of hepatocellular carcinomas with an activated FGFR4 signaling pathway. Cancer Discov 2015; 5: 424-437.

65. Bhushan B, Borude P, Edwards G, Walesky C, Cleveland J, Li F et al. Role of bile acids in liver injury and regeneration following acetaminophen overdose. Am J Pathol 2013; 183: 1518-1526.

66. Espeillac C, Mitchell C, Celton-Morizur S, Chauvin C, Koka V, Gillet C et al. S6 kinase 1 is required for rapamycin-sensitive liver proliferation after mouse hepatectomy. J Clin Invest 2011; 121: 2821-2832.

67. Berasain C, García-Trevijano ER, Castillo J, Erroba E, Lee DC, Prieto J et al. Amphiregulin: an early trigger of liver regeneration in mice. Gastroenterology 2005; 128: 424-432.

68. Wang X, Bhattacharyya D, Dennewitz MB, Kalinichenko VV, Zhou Y, Lepe R et al. Rapid hepatocyte nuclear translocation of the Forkhead Box M1B (FoxM1B) transcription factor caused a transient increase in size of regenerating transgenic hepatocytes. Gene Expr 2003; 11: $149-162$.

69. Paranjpe S, Bowen WC, Mars WM, Orr A, Haynes MM, DeFrances MC et al. Combined systemic elimination of MET and epidermal growth factor receptor signaling completely abolishes liver regeneration and leads to liver decompensation. Hepatology 2016; 64: 1711-1724.

70. Bhushan B, Chavan H, Borude P, Xie Y, Du K, McGill MR et al. Dual role of epidermal growth factor receptor in liver injury and regeneration after acetaminophen overdose in mice. Toxicol Sci 2017; 155: 363-378.

71. James LP, Lamps LW, McCullough S, Hinson JA. Interleukin 6 and hepatocyte regeneration in acetaminophen toxicity in the mouse. Biochem Biophys Res Commun 2003; 309: 857-863.

72. Sanchis-Gomar F, Pareja-Galeano H, Santos-Lozano A, Garatachea N, Fiuza-Luces C, Venturini $L$ et al. A preliminary candidate approach identifies the combination of chemerin, fetuin-A, and fibroblast growth factors 19 and 21 as a potential biomarker panel of successful aging. Age (Dordr) 2015; 37: 9776.

73. Wang X, Krupczak-Hollis K, Tan Y, Dennewitz MB, Adami GR, Costa RH. Increased hepatic Forkhead Box M1B (FoxM1B) levels in old-aged mice stimulated liver regeneration through diminished p27Kip1 protein levels and increased Cdc25B expression. J Biol Chem 2002; 277: 44310-44316.

74. Alder $\mathrm{O}$, Cullum R, Lee $\mathrm{S}$, Kan AC, Wei W, Yi Y et al. Hippo signaling influences HNF4A and FOXA2 enhancer switching during hepatocyte differentiation. Cell Rep 2014; 9: 261-271.

75. Hatzis P, Kyrmizi I, Talianidis I. Mitogen-activated protein kinase-mediated disruption of enhancer-promoter communication inhibits hepatocyte nuclear factor 4alpha expression. Mol Cell Biol 2006; 26: 7017-7029.

76. Alvarez-Sola G, Uriarte I, Latasa MU, Urtasun R, Barcena-Varela M, Elizalde M et al. Fibroblast growth factor 15/19 in hepatocarcinogenesis. Dig Dis 2017; 35: 158-165.

77. Baulies A, Ribas V, Núñez S, Torres S, Alarcón-Vila C, Martínez L et al. Lysosomal cholesterol accumulation sensitizes to acetaminophen hepatotoxicity by impairing mitophagy. Sci Rep 2015; 5: 18017.

78. Inaba K, Inaba M, Romani N, Aya H, Deguchi M, Ikehara S et al. Generation of large numbers of dendritic cells from mouse bone marrow cultures supplemented with granulocyte/macrophage colony-stimulating factor. J Exp Med 1992; 176: 1693-1702.

79. Rogers GW, Brand MD, Petrosyan S, Ashok D, Elorza AA, Ferrick DA et al. High throughput microplate respiratory measurements using minimal quantities of isolated mitochondria. PLOS ONE 2011; 6: e21746.

80. Argemí J, Kress TR, Chang HCY, Ferrero R, Bértolo C, Moreno H et al. X-box binding protein 1 regulates unfolded protein, acute-phase, and DNA damage responses during regeneration of mouse liver. Gastroenterology 2017; 152 1203-1216 e15.

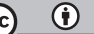

Cell Death and Disease is an open-access journal published by Nature Publishing Group. This work is licensed under a Creative Commons Attribution 4.0 International License. The images or other third party material in this article are included in the article's Creative Commons license, unless indicated otherwise in the credit line; if the material is not included under the Creative Commons license, users will need to obtain permission from the license holder to reproduce the material. To view a copy of this license, visit http://creativecommons.org/licenses/by/4.0/

(C) The Author(s) 2017 